\title{
Invited Articles from HTSMA-2nd International Conference on High-Temperature Shape Memory Alloys
}

The fact that Shape Memory and Superelasticity has decided to publish another special issue dedicated to hightemperature shape memory alloys-after just three yearsattests to the rapid progress made in the field. The materials that are addressed in this issue range from NiTi and its derivatives to $\mathrm{Co}-\mathrm{Ni}-\mathrm{Ga}-$ and $\mathrm{Ti}-\mathrm{Ta}-$ based systems. Microstructural instability was identified as one of the major roadblocks to the widespread use of these materials early on. Some of the papers contained in this issue address this aspect and advance our understanding of the underlying mechanism that govern functional degradation. Both intense modeling efforts and the use of advanced characterization tools - that range from production of thin film libraries to diffraction techniques-were key in this process.

These studies also demonstrate how the knowledge gained can be exploited to increase the materials' performance through alloying, processing, and heat treatment. Often, the performance of materials produced in a laboratory environment cannot be realized under large-scale production conditions. A case in point are the excellent properties obtained for shape memory single crystals. Two of the papers directly address this issue and demonstrate how the microstructure can be tailored to realize single crystal performance in polycrystalline materials.

Last, but not least, the models and the expected performance of the materials need to be validated. Thus, quite a few of the papers contain data on materials' response under thermal and cyclic mechanical loading scenarios. The papers also nicely demonstrate the progress made, with some of the materials already substantially exceeding the widely used initial definition of a high-temperature shape alloy. Apparently, the industry is already beginning to use

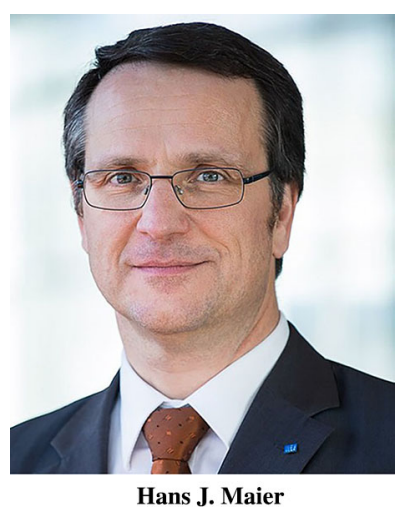

some of these alloys for advanced applications. Thus, one may expect additional thrust for the research in this exciting field. In fact, it is hoped that this special issue will not only provide an overview on the state-of-the-art technology but will again trigger new research in this intricate scientific field.

Finally, I would like to thank all those who contributed as authors or reviewers and those who worked behind the scenes. Their combined effort has finally made this special issue possible. I hope you do enjoy reading the papers as much as I did.

\section{Hans J. Maier}

Guest Editor

Institut für Werkstoffkunde (Materials Science)

Leibniz Universität Hannover

Publisher's Note Springer Nature remains neutral with regard to jurisdictional claims in published maps and institutional affiliations. 